Supplement of Clim. Past Discuss., 11, 4943-4984, 2015

http://www.clim-past-discuss.net/11/4943/2015/

doi:10.5194/cpd-11-4943-2015-supplement

(C) Author(s) 2015. CC Attribution 3.0 License.

(c) (i)

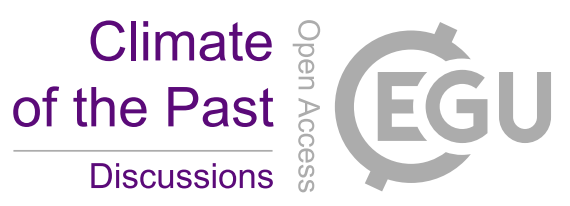

Supplement of

\title{
Frequency and intensity of palaeofloods at the interface of Atlantic and Mediterranean climate domains
}

\section{B. Wilhelm et al.}

Correspondence to: B. Wilhelm (bruno.wilhelm@ujf-grenoble.fr)

The copyright of individual parts of the supplement might differ from the CC-BY 3.0 licence. 
Flood date Affected rivers

$>3$ September 2012 Guil

28 May $2008 \quad$ Guil

13 June 2002

Torrents of Segure and other

$>15$ July 2002

$>15$ October 2000

13 June 2000

$>$ July 1992

11 June 1978

5 May 1973

$>1$ November 1963

21 May 1959

$>$ Summer 1959

13 June 1957

$>$ October 1953

$>29$ Sept. 1953

$>1$ July 1953

8 June 1953

14 May 1948

$>4$ August 1938 1932

Guil and other

Guil and Torrent of Segure

Torrent of Bouchouse

Guil

Undefined

Guil

Guil

Guil and Torrent of Segure

Torrent of Jalinette

Guil

Torrent of Jalinette

Guil

$>9$ July 1932

$>1$ September 1920 G

29 May 1856

$>6$ August 1852

15 October 1839

$>13$ Sept. 1810

13 October 1810

$>10$ October 1791

9 October 1790 1789

orrent of Segure

Torrent of Maloqueste

Guil

Guil

Guil

Guil

Guil and Torrent of Segure

Guil

Guil and Torrent of Chapelle

Guil

Guil

07 Sept $1788 \quad$ Guil

$>7$ September 1787 Guil

$>4$ October 1751
Spatial extent of the flood

Victim Damage Disruption

Ristolas and villages downstream

Ristolas and villages downstream $Y$

Ristolas

Ristolas and villages downstream $N$

Ristolas and villages downstream $N$

Ristolas and villages downstream $\mathrm{N}$

Ristolas

Ristolas and villages downstream $\mathrm{N}$

Ristolas and villages downstream $\mathrm{N}$

Ristolas

Ristolas and villages downstream N

Ristolas and villages downstream $\mathrm{N}$

Ristolas and villages downstream $\mathrm{N}$

Ristolas

Ristolas and villages downstream $\mathrm{N}$

Ristolas

Ristolas and villages downstream

Ristolas and villages downstream

Ristolas

Ristolas

Ristolas and villages downstrean

Ristolas and villages downstream $\mathrm{N}$

Ristolas and villages downstream $\mathrm{N}$

Ristolas and villages downstream N

Ristolas and villages downstream $\mathrm{N}$

Ristolas and villages downstream $\mathrm{N}$

Ristolas and villages downstream $\mathrm{N}$

Ristolas and villages downstream N

Ristolas and villages downstream $\mathrm{N}$

Ristolas and villages downstream N

Ristolas and villages downstream $\mathrm{N}$

Ristolas and villages downstream $\mathrm{N}$

Ristolas and villages downstream - N
Details on the hydro-meteorological causes

Easterlies winds with heavy rainfalls in the upper part of catchment Heavy rainfall event

Heavy rainfalls mainly in the upper part of the catchment Easterlies winds with heavy rainfalls in the upper part of the catchment

5 days of heavy rainfalls with increased rainfall depths the last 2 days

Heavy rainfalls mainly in the upper part of the catchment

Violent thunderstorms

Heavy rainfalls, thunderstorm, snowmelt

Heavy rainfall event

Heavy rainfall event during 3 days

Violent thunderstorms and snowmelt

Rainfall depth of $244 \mathrm{~mm}$ in 3 days, with snowmelt

Violent thunderstorms

Heavy rainfalls over a long period before the flood event Heavy rainfall events

Heavy rainfall events

Heavy rainfall events during 8 days 
Table S1. List of historical flood events which runs through the village of Ristolas, located $8 \mathrm{~km}$ downstream from Lake Foréant (from the free-access database of the ONF-RTM, http://rtmonf.ifn.fr/). The arrows in the first row highlight the floods that occurred in summer and fall, i.e. that may be recorded in the lake sediments because this period corresponds to the ice-free season of Lake Foréant. N means No, Y means Yes and U, Uncertain.

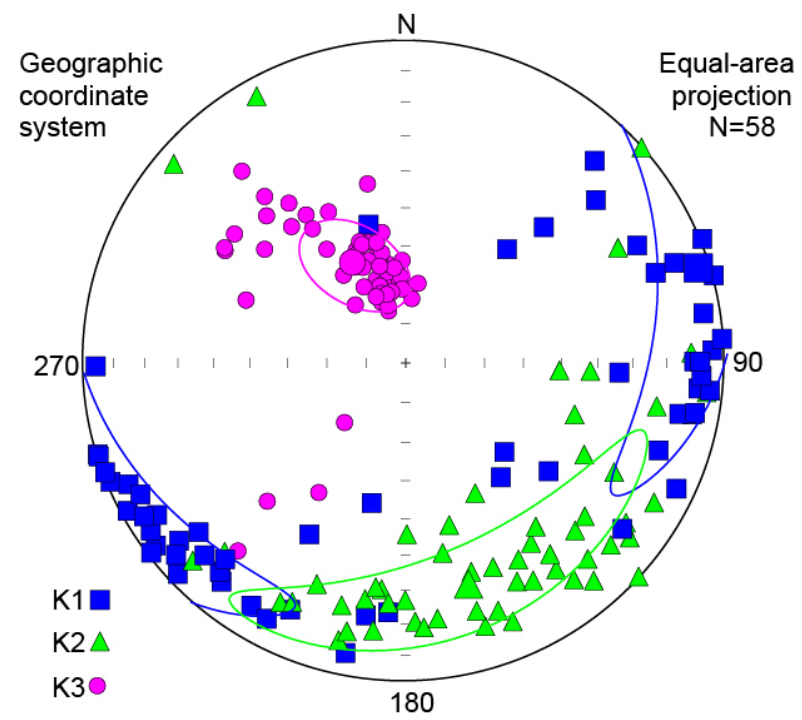

Fig. S1. Results of Anisotropy of Magnetic Susceptibility for core FOR13P4: stereo plot of the main axes direction. Notice that the K3 is well grouped and close to the vertical except some points associated with MMITs. 
FOR13 P3 $88 \mathrm{~cm}$

$M A D=2,17$

Units: $2 \cdot 10^{-4} \mathrm{~A} / \mathrm{m}$
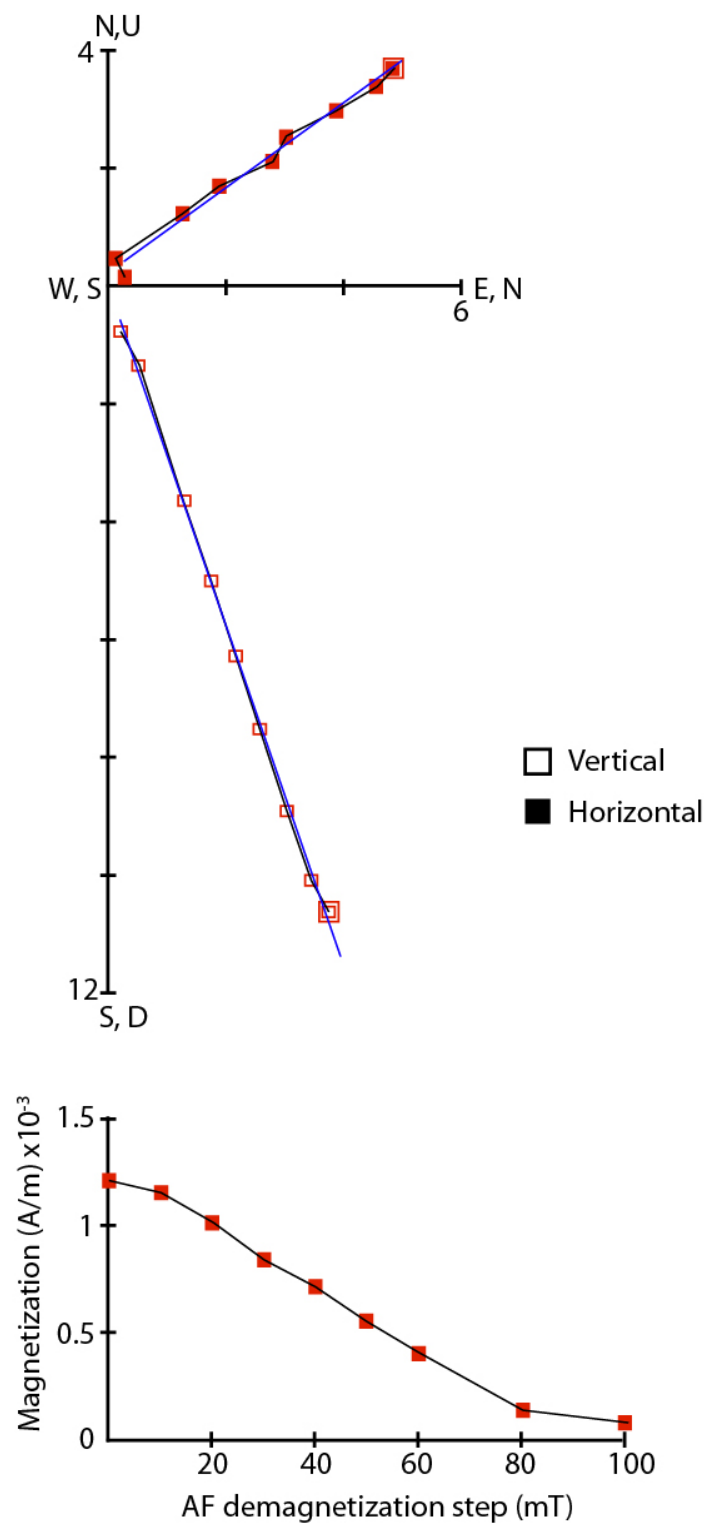

FOR13P1 $10 \mathrm{~cm}$

MAD $=1,67$

Unit: $10^{-4} \mathrm{~A} / \mathrm{m}$
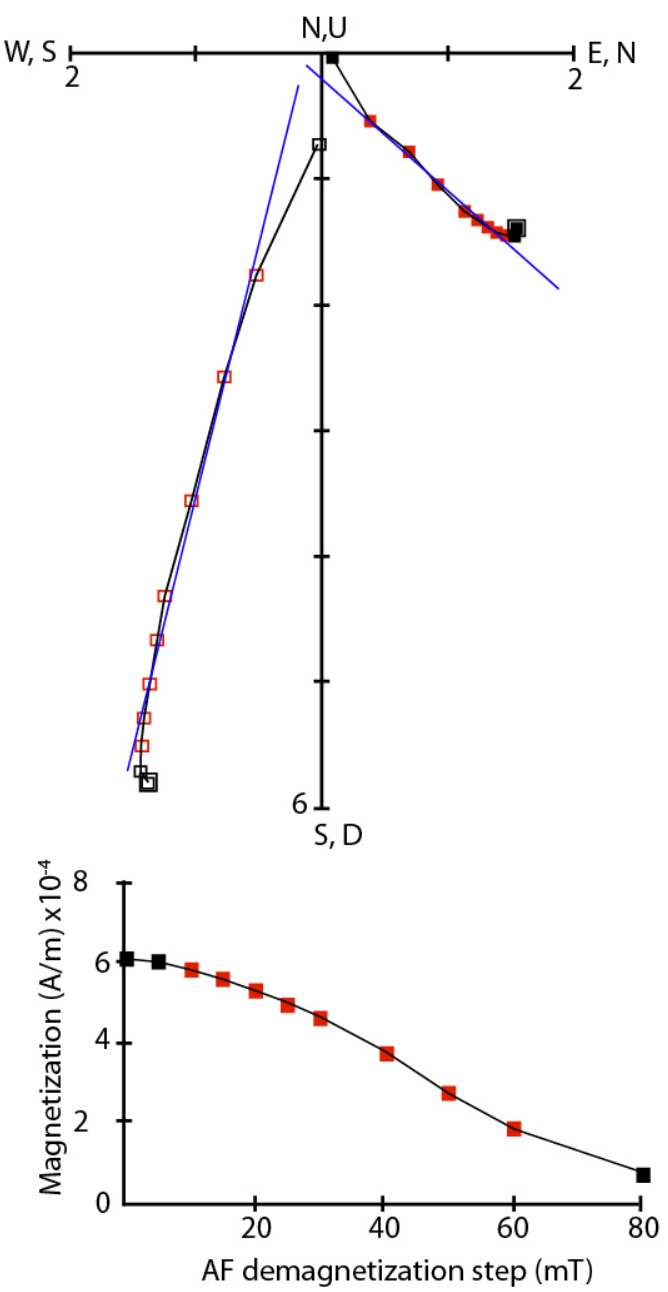

Fig. S2. Example of stepwise alternating field demagnetization of NRM (orthogonal vector projections and intensity curves) for representative samples. Solid (open) symbols are horizontal (vertical) plane projections. 
A

\section{Flood frequency \\ vs. grazing pressure}

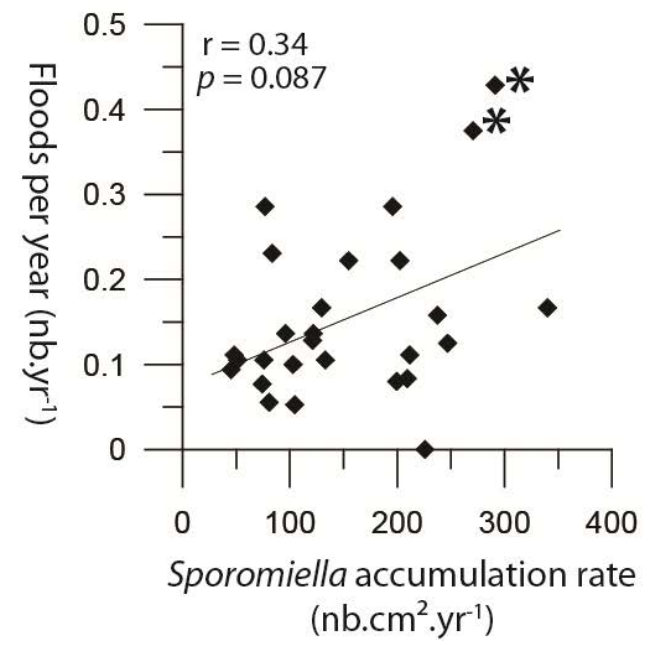

B

Flood intensity

vs. grazing pressure

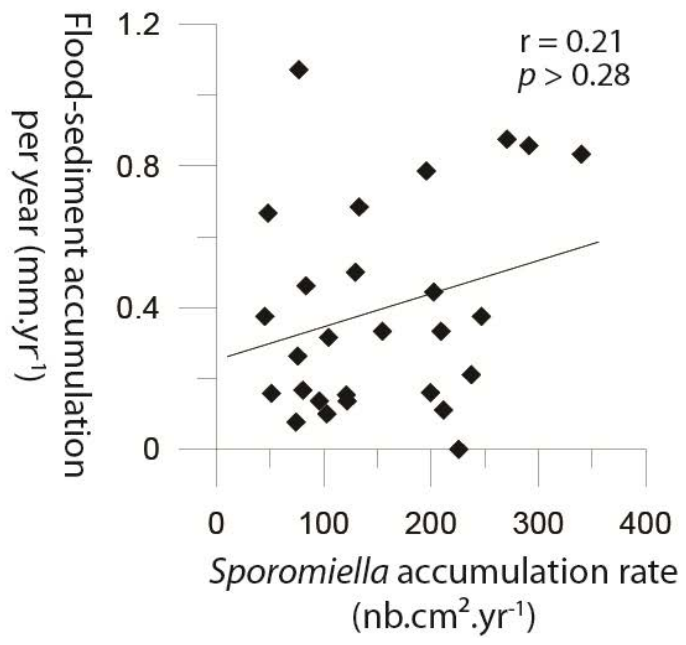

Fig. S3. Representation and correlation coefficients (r) of relations between (A) Sporormiella accumulation rates (nb.cm². $\left.\mathrm{yr}^{-1}\right)$ and floods frequency (nb.yr $\left.{ }^{-1}\right)$, and between (B) Sporormiella accumulation rates (nb. $\mathrm{cm}^{2} \mathrm{yr}-1$ ) and flood-sediment accumulation (mm.years ${ }^{-1}$ ). The stars identified two samples, dated from 1734 to $1760 \mathrm{AD}$, with both high grazing pressure and high flood frequency. Levels of significance ( $p$ values) were determined using a Spearmantest. 